\title{
Pre-service Teachers' First Time Experiences With A New Course Management System
}

Zafer Unal, USF St. Petersburg, USA

Aslihan Unal, Usak University, Turkey

\begin{abstract}
From a student's perspective, course management systems are a step above a classroom website. Information sharing is no longer static; these systems utilize tools that allow information to be passed in many directions and in a number of different ways. They have the most important task addressing the needs of the ultimate end user, the learner. This study investigated 71 pre-service teachers' first time experiences and satisfaction from a pilot test of a new course management system (Moodle) implemented during an online educational technology course.
\end{abstract}

Keywords: Course Management Systems; Learning Management Systems

\section{INTRODUCTION}

$\mathrm{n}$ the current market space, there are many commercially available course management systems from which to choose. The primary contender in this market space is Blackboard, especially when its acquisition of its main competitor, WebCT, is taken into consideration. The open source community has also been active in creating alternative course management system choices that are free of licensing costs. Currently, the most popular open source course management system is Moodle. Moodle is a software package for producing internet-based courses and web sites. It is a world-wide ongoing development project designed to support a social constructionist framework of education (Moodle, 2010). Once installed, Moodle can be configured to use the tens of modules including assignment, chat, choice, forum, glossary, lesson, quiz, resource, survey, wiki, workshop, etc. An institution now has the choice between many competing learning management systems, both from proprietary software manufacturers and open source projects. It is not enough, however, to just pick a package based on its price or feature list. Institutions considering implementing a Course Management System must carefully evaluate it before putting it to use with a student population (Colace, Santo, \& Vento, 2002; Iding, Auernheimer, Crosby, \& Klemm, 2002).

At the time of this study, there were three prior works that helped to provide a foundation and additional insight into this study focusing on student experiences with Moodle, including comparison studies BlackBoard versus Moodle. The first is unpublished raw data collected from California State University (Munoz K. \& Duzer J., 2004). They conducted a study using a single fully online course with 35 students. The study came to conclusions that on any one feature compared between the two course management systems under investigation, there was not always a clear winner; but in the aggregate, students were more satisfied with their experience with Moodle and would prefer its use over BlackBoard. The second work considered was a conference paper (Bremer D. \& Bryant R., 2005) aimed to analyze the reflections of the instructor, system administrator and the students involved in a trial use of Moodle versus BlackBoard. After the study, instructors reported that the interface to Moodle seemed reasonably straight forward; resources, GradeBook and discussion board was more functional in Moodle; the students also favored Moodle over BlackBoard on most counts; and system administrators reported that Moodle was stable and relatively quick on the hardware they used for the trial. The third study was again a conference paper (Machado, M. \& Tao, E., 2007) used to compare the usability and effectiveness of two competing course management systems (Moodle and BlackBoard) by establishing a control group that only used the proprietary 
solution and two study groups, a faculty group and a student group that used the open source solution. The results of the study indicated that the students in the pilot project preferred the Moodle course management. They rated its ease of use higher and $75 \%$ of them would prefer to use it over Blackboard in the future courses that they enroll in at the university.

The goal of this study is to explain and discuss pre-service teachers' first time experiences and their level of satisfaction with the use of Moodle course management system during their educational technology course offered online. In addition, the study also aimed to investigate whether Moodle could warrant a more formal consideration as an additional alternative to the institution's current course management system, BlackBoard. The study attempted to answer the following research questions:

- $\quad$ How do pre-service teachers describe their course satisfaction with use of Moodle?

- How do pre-service teachers describe their experiences with use of Moodle?

- Does Moodle bring comparable results to warrant formal consideration as an additional alternative to the institution's current course management system, BlackBoard?

\section{METHODOLOGY}

The Moodle was installed on University's servers located on campus IT building and administered by Academic Technologies personnel. After the installation, the instructor prepared the course in Moodle by exporting the modules from BlackBoard into Moodle and tested the course for usability before the semester started. The 15week Fall semester version of the course included the following topics: the critical evaluation of educational software; conceptualizing uses of computers in the classroom in terms of computer-directed instruction, computerenhanced instruction, and computer-managed instruction; understanding hardware; using and applying commercial courseware, general applications software, word processors, database managers, etc., and disk operating systems. Meanwhile, the researchers created the online survey and interview forms and obtained human subjects approval prior to the course.

The participants for the study included 71 pre-service teachers who enrolled in the educational technology courses during Fall 2008. At the end of the semester, the researchers provided the links to the online surveys and invited six randomly selected course participants for an interview to discuss their experiences with Moodle. The survey conducted after the completion of the course consisted of four sections: 1) demographic information, 2) overall satisfaction from the course, 3) experience with Moodle, and 4) evaluation of the instructor. The survey also allowed participants to provide additional comments or suggestions on any issues that were not addressed in the previous four sections of the survey. The interview also included similar questions, the interview lasted about 45 minutes, and students were informed that the interview would not affect their course grade, so they were encouraged to speak freely about their thoughts and recommendations on the study.

\section{RESULTS}

Seventy-one students enrolled in the course have participated in the study by completing the survey at the end of the course. The randomly selected six students, who were invited for the interview, also participated (Table $1)$.

Table 1: Demographics

\begin{tabular}{lll}
\hline & Survey $(\mathbf{n = 7 1})$ & Interview $(\mathbf{n}=\mathbf{6})$ \\
\hline Age & Mean=28.09, SD=9.79 & Mean=32.11, SD=9.24 \\
Gender & Males=9, Females=62 & Males=1, Females=5 \\
Is EME2040 your first online course? & Yes=2, No=69 & Yes=1, No=5 \\
\hline
\end{tabular}

This section will first provide survey results in tables and then provide feedback and comments received from open-ended questions from the surveys and the focus group interview. The results provided in Table 2 show the students' overall course satisfaction, indicating that "the course was a success." They were all satisfied with the 
course, course assignments and projects. Course content was appropriate to their major and the course improved their computer knowledge and skills.

Table 2: Suvey Section 2 - Overall Course Satisfaction

\begin{tabular}{|c|c|c|}
\hline $\begin{array}{c} \\
\text { Questions } \\
\end{array}$ & Mean & SD \\
\hline The course helped me improve my educational technology knowledge & 4.76 & .436 \\
\hline The course helped me improve my educational technology skills & 5.00 & .000 \\
\hline The course documents - lessons or lecture notes used in this class were helpful for my learning & 4.52 & .512 \\
\hline The sample assignments provided with each lesson were helpful & 4.81 & .402 \\
\hline The assignments and/or projects in this course facilitated my learning & 4.71 & .463 \\
\hline The number of assignments for each lesson was appropriate & 5.00 & .000 \\
\hline The course content was relevant to my future program/job & 4.95 & .218 \\
\hline The course adequately covered its stated objectives & 4.86 & .359 \\
\hline I achieved the goals I had when I started this course & 4.86 & 3.59 \\
\hline All things considered, I am satisfied with this course & 4.52 & .602 \\
\hline I recommend this course to others & 4.95 & .218 \\
\hline
\end{tabular}

Interpretation Scale: Strongly Disagree (1), Disagree (2), Neutral (3), Agree (4), Strongly Agree (5)

The results provided in Table 3 confirm that the students' first time experience with using Moodle Course Management System was very positive. They were all satisfied with the Moodle system as they found it to be easy to use and as an efficient platform to interact with the teacher and other course participants. They also indicated that they would prefer Moodle over BlackBoard for their next online course.

Table 3: Suvey Section 3 - Experience with Moodle

\begin{tabular}{lcc}
\hline \multicolumn{1}{c}{ Questions } & Mean & SD \\
\hline Moodle course website was easy to use & 4.95 & .218 \\
Moodle course website was easy to navigate through the course & 4.81 & .402 \\
Moodle course website was well organized & 4.95 & .218 \\
Moodle course website assisted my interaction with my instructor & 4.86 & .359 \\
Moodle course website assisted my interaction with my classmates & 4.76 & .436 \\
Discussion board on our Moodle course website was easy to use & 4.95 & .218 \\
Assignment submission tool on our Moodle course wesbite was easy to use & 5.00 & .000 \\
Grades tool on our Moodle course website was easy to use & 4.81 & .402 \\
Our Moodle course website was easier to use than BlackBoard & 4.62 & .590 \\
I would take another course offered via Moodle in the future & 4.90 & .301 \\
If I were to given an option between BlackBoard and Moodle for my next online course, I prefer Moodle & 4.90 & .301 \\
\hline Inter
\end{tabular}

Interpretation Scale: Strongly Disagree (1), Disagree (2), Neutral (3), Agree (4), Strongly Agree (5)

The results provided in Table 4 indicate that students were also satisfied that the course instructor was knowledgeable about the subject matter, available to assist students, and respected the students.

Table 4: Suvey Section 4 - About Instructor

\begin{tabular}{|c|c|c|}
\hline $\begin{array}{ll} & \text { Questions } \\
\end{array}$ & Mean & SD \\
\hline The instructor's competency in knowledge of the subject material was & 4.76 & .436 \\
\hline The instructor's skills in teaching thi online course was & 4.71 & .561 \\
\hline The instructor's interest in your learning was & 4.71 & .463 \\
\hline The instructor's fairness in assessing your progress in the course was & 4.76 & .436 \\
\hline Expression of expectations for performance was & 5.00 & .000 \\
\hline Availability to assist students was & 4.95 & .218 \\
\hline Promptness of instructor's response was & 4.86 & .359 \\
\hline
\end{tabular}


Results of open-ended questions on surveys and focus group interview results are included in Table 5. The participants' feedback and recommendations are grouped into the same four themes. While most of the responses were positive around the three themes, participants also provided their recommendations to increase the efficiency of the LMS used during the course (Table 5).

Table 5: Student Responses to Open-ended Questions

\begin{tabular}{ll}
\hline Category & \multicolumn{1}{c}{ Statements } \\
\hline Satisfaction & I learned a lot. I know, I just came from ABC University where I had to take a technology class and \\
I was kind of frustrated. I was like why do I have to take another technology class. But I am really \\
glad I did because I really liked it and I am really going to benefit, I really learned from it. An I, um, \\
I thought he did a great job. \\
The directions were simple and easy to follow. Communication was also great, something that is \\
sometimes missed in Internet courses. I enjoyed the challenge of all the projects. \\
Additional practice items for the concepts covered, I think this was a great introduction to the \\
concepts I'd like additional opportunities to practice the concepts. \\
All things considered, it was prepared very well \\
- I liked how easy it was to get around, unlike BlackBoard; I learned what I needed from this website \\
in a day versus BlackBoard that I'm still learning how to get around. \\
I like the fact that it was very easy and clear cut. There were no difficult twists and turns to turn in \\
assignment. What I did not like was the limit on the picture. \\
I liked how well organized and easy-to-use it was, and how it had each week lessons mapped out so \\
well. There really wasn't anything I did't like. \\
I think the course website was a lot better than BlackBoard. I had no problems at all with the course \\
website. I thought it was very self explanatory on the website. All your links were exactly where you \\
expected them and you know on BlackBoard it is not the same. I prefer the website (Moodle) over \\
BlackBoard. \\
Online chat activity dates/times should be surveyed at the beginning of the semester for larger \\
participation. \\
Incoming emailes from the discussion board should be reduced \\
Image size on participants' photo should be larger
\end{tabular}

\section{DISCUSSION}

In recent years, Learning Management Systems (LMSs) have matured to the point that they're now considered critical software for many colleges and universities. There are currently many commercially (BlackBoard, Desire2Learn) and open source (Moodle, Sakai) course management systems available for educational institutions to choose. However, it is a known fact that the decision of what LMS to choose for students and instructors has already been made most of the time. This means that a new student or instructor will automatically need to adopt the system available at the new institution. Changing a LMS that has already been in use for years is definitely a big task. Before new systems can be considered effective, the user experience must be studied and analyzed to provide the optimum solution to meet pedagogical needs of both faculty and students (Machado M. \& Tao E., 2007).

Spady (1994), an educational researcher who spearheaded the development of outcomes-based education, suggests that the ability to demonstrate learning is the key point. This demonstration of learning involves a performance of some kind in order to show significant learning, or learning that matters. Also, student course satisfaction reflects the effectiveness of all aspects of the educational experience. The goal is that all students who complete a course express satisfaction with course rigor and fairness, with professor and peer interaction, and with support services (Brown, 2000).

The participants' feedback from the survey and interview data collected during this study indicated that students confirmed their learning outcomes and course satisfaction positively. They felt that Moodle was easy to use, well organized, and increased interaction with the instructor and other students. The majority of the participants 
indicated that Moodle was actually easier to use than BlackBoard, that they would not hesitate to take their future courses, if offered with Moodle, and furthermore, they actually prefer their next online course via Moodle as well.

This study has both internal and external implementations. At the end of this study, the researchers concluded that use of Moodle in this particular online course can be an alternative to the current course management system. In fact, now that the pilot has showed that Moodle is as effective as BlackBoard, researchers already started to share their experiences with other faculty and conduct another pilot study based on bigger sample and numerous online courses involving other faculty because the product shows significant potential and should be seriously considered for further investigation.

This study adds to the growing body of studies that are done as the initial attempt to research to see if an open source course management system (Moodle) warrants consideration as an alternative to the institutions' current Course Management Systems. Rather than discussing the politics involved with the selection of a LMS (open source versus closed source, free versus fee-based), this article is an example of a pilot study on pre-service teachers' first time experiences with Moodle during their educational technology course, focusing on course outcomes, course satisfaction, experience with Moodle, and their recommendations. This study, with the included instruments, can be used as a guide to be easily replicated to help educators to test their own findings, at their own institutions by exploring additional concepts, implementing supplementary models to the conceptual framework, expanding the population of interest, analyzing additional educational settings, and using other research designs.

This study has certain limitations. The study has a small sample size, includes only one course and focuses only on students' perspectives of the use of Moodle. Replicate studies are recommended for educators to conduct their own tests of the alternatives or other studies focusing on pedagogical value, financial concerns, support issues, assessment criteria for accreditation, integration with the information technology services, and long-term viability.

\section{AUTHOR INFORMATION}

Zafer Unal is an assistant professor of childhood education, serving as assessment coordinator for the college of education, coordinating the college wide assessment system at University of South Florida, St. Petersburg, USA.

Aslihan Unal is an assistant professor of elementary education for the college of education, Usak University, Turkey.

\section{REFERENCES}

1. Bremer, D. \& Bryant, R. (2004). “A Comparison of two learning management Systems: Moodle vs. Blackboard", Proceedings of the $18^{\text {th }}$ Annual Conference of the National Advisory Committee on Computing Qualifications. pg135-1390CE

2. Bremmer, D., \& Bryant, R. (2005). A comparison of two learning management systems: Moodle vs. Blackboard. New Zealand Journal of Applied Computing and Information Technology, 2005, 135-139.

3. Brown, B. L. (2000). Web-based training. ERIC Clearinghouse on Adult, Career, and Vocational Education. Retrieved on October 10, 2003 from http://www.ericacve.org/docgen.asp?tbl=digests\&ID=103

4. Colace, F., Santo, M. D., \& Vento, M. (2002). Evaluating on-line learning platforms: a case study. Paper presented at the 36th Hawaii International Conference on System Sciences, Big Island, Hawaii.

5. Iding, M. K., Auernheimer, B., Crosby, M. E., \& Klemm, E. B. (2002). Guidelines for designing evaluations of web based instructional materials. Paper presented at the 36th Hawaii International Conference on System Sciences, Big Island, Hawaii.

6. Machado, M. \& Tao, E. (2007). "Blackboard vs. Moodle: Comparing User Experience of Learning Management Systems", Proceedings of the $37^{\text {th }}$ Annual Conference of the Frontiers in education conference - global engineering: knowledge without borders, opportunities without passports. pg S4J-7S4J-12

7. Moodle (2010). “About Moodle”. Retrieved on June 05, 2010 from http://docs.moodle.org/en/About_Moodle 
8. Munoz, K. \& Duzer, J. (2004) Blackboard versus Moodle: A comparison of satisfaction with online teaching and learning tools. Retrieved, June 05, 2010, from http://www.humboldt.edu/ jdv1/moodle/all.htm

9. Spady, W. 1994. "Choosing outcomes of significance." Educational Leadership, 51, (6) 18-22 (March).

10. Wikipedia (2010). "Moodle". Retrieved on June 05, 2010 from http://en.wikipedia.org/wiki/Moodle

\section{NOTES}

